www.nature.com/ebd

\title{
toolbox
}

\section{Asking the right question right}

\section{Derek Richards}

\section{Centre for Evidence-based Dentistry, Oxford, UK}

In the first evidence-based dentistry supplement, Richards and Lawrence ${ }^{1}$ outlined the essential steps in the process of evidence-based clinical decision-making (Figure 1). The first of these is to identify (focus) the clinical problem or problems encountered into a well-defined question.

A well-defined question can be compared with hypothesis generation before embarking on any study or trial. A focussed question (as with a carefully thought out hypothesis) has a number of advantages:

- It helps clarify in your own mind the problem and the information required to solve it.

- It helps define the type of evidence needed.

- It helps provide terms to make searching for evidence more effective.
Questions can arise from a number of sources:

Day to day practice: a question from a patient about a particular treatment, a trend you observe from your patients, uncertainty about how to treat a particular problem or condition. A condition that you have not encountered before, or you may wish to compare the cost effectiveness of different treatments.
Identify Clinical Problem

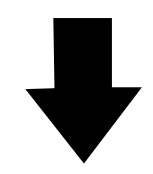

Search for Evidence

Discard Poor Evidence

Store Good Evidence
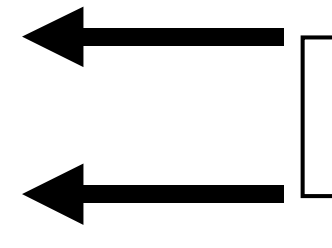

Make Sense of Evidence

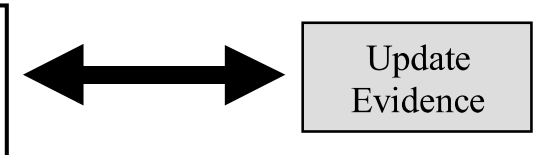

Act on Evidence

Figure 1 Evidence-based clinical practice 
A group initiative: for example an audit or peer review project. A topical issue e.g. 'tooth whitening' or a professional desire to make your practice evidence-based. You may wish to compare the cost effectiveness of approaches taken by two practices or practitioners.

A clinical article or meeting: an article in a journal or postgraduate meeting may have stimulated a need for information about an approach to treatment or a new material.

Personal development: you may decide that you need to update your knowledge in a particular area of your clinical practice that you have not considered for a while.

The well-defined clinical question has four key components ${ }^{2}$ :

- The type of patient or clinical problem presented (patient or problem)

- What you are doing to the patients. The treatments, manoeuvre or diagnostic test you are planning to use (intervention).

- The intervention in many controlled and randomised controlled trials is compared with either the previous 'best therapy' or a placebo. This is the comparison intervention.

- The clinical outcome(s) you are hoping for or the outcome of interest.

This is shown in table 1 (http:// cebm.jr2.ox.ac.uk/focusquest.html).

\section{Consider the following clinical situation}

A female patient presents at the surgery shortly after learning that she is pregnant. She is concerned about the condition of her teeth and she is worried that she might loose some of them during pregnancy as friends have told her about the old wives' tale that you lose a tooth for every pregnancy.

Let us consider the four elements in turn as a worked example:

\begin{tabular}{|c|c|c|c|c|}
\hline & $\begin{array}{l}\text { 1. Patient } \\
\text { (or problem) }\end{array}$ & $\begin{array}{l}\text { 2. Intervention (or } \\
\text { cause, prognosis) }\end{array}$ & $\begin{array}{l}\text { 3. Comparison } \\
\text { (or control) }\end{array}$ & 4. Outcome(s) \\
\hline Ask: & $\begin{array}{l}\text { How would I } \\
\text { describe a group of } \\
\text { patients similar to } \\
\text { mine? }\end{array}$ & $\begin{array}{l}\text { Which main } \\
\text { intervention am I } \\
\text { considering? Be } \\
\text { specific. }\end{array}$ & $\begin{array}{l}\text { What is the main } \\
\text { alternative? Be } \\
\text { specific. }\end{array}$ & $\begin{array}{l}\text { What can I hope to } \\
\text { accomplish? }\end{array}$ \\
\hline Example: & $\begin{array}{l}\text { In patients with } \\
\text { (dental problem - } \\
\text { e.g. caries/ } \\
\text { peridontal disease) }\end{array}$ & $\begin{array}{l}\text {... would using } \\
\text { (dental product) }\end{array}$ & $\begin{array}{l}\ldots \text { when compared } \\
\text { with standard } \\
\text { therapy alone ... }\end{array}$ & $\begin{array}{l}\text {... lead to lower } \\
\text { (clinical measure) }\end{array}$ \\
\hline
\end{tabular}

\section{Patient or problem}

A useful tip to help you decide this is to ask yourself, "how would I describe a group of patients similar to mine?". You will need to decide whether it is the patient group you wish to identify OR the problem. Sometimes the other elements of the question will give you the clue. The patient is pregnant, and she is concerned that she may loose teeth as a result. The outcome that she is concerned with is tooth loss. So here we should consider the patient or patient group; this is pregnant or potentially pregnant females. Therefore the patient group we are considering is women of child-bearing age.

\section{Intervention and comparison intervention:}

Here you need to ask yourself, "what is the main intervention you are considering?" and be specific. In our case the patient is concerned about tooth loss during pregnancy so the intervention we need to consider is pregnancy.

Our next element would the comparison. Here you need to ask yourself, "what is the main alternative?" The alternative to pregnancy is not being pregnant!

\section{Outcome:}

The final element of the question is the outcome we are looking for. Here we need to ask ourselves, "what can we hope to accomplish or what could the exposure really affect?". As discussed above, the major outcome of concern here for the patient is tooth loss.

So taking into account the four main elements above we can now construct the following well-focused clinical question from our old wives tale.

\section{EVIDENCE-BASED QUESTION: In women of child bearing age, does pregnancy result in increased tooth loss?}

Not all patient problems fit neatly into this format but, as mentioned at the outset, it helps clarify the problem in your own mind. Once the problem is clarified, it is much easier to identify the type of evidence and information required to solve it. This in turn makes searching databases for this evidence more effective, which makes it far more likely to result in a useful answer. It is these useful answers that both the clinician and patients are looking for.

1. Richards D, Lawrence A. Evidence-Based Dentistry. Evidence-Based Dentistry 1998; 1:7-10.

2. Richardson W Wilson M, Nishikawa J, Hayward RS. The well-built clinical question: a key to evidence-based decisions [editorial]. ACP Journal Club 1995; 123:A123. 